\title{
Fatal intraperitoneal haemorrhage of hepatic origin
}

\author{
A. Fidas-Kamini and A. Busuttil \\ Department of Pathology, Western General Hospital, Edinburgh EH4 2XU, UK.
}

\begin{abstract}
Summary: Eight cases of fatal haemoperitoneum due to liver bleeding are reported. Two followed trauma (liver biopsy and cholecystectomy). The remaining six were spontaneous, 5 being due to malignant liver disease. The sixth case due to polycystic liver disease appears to be unique. The aetiology and importance of spontaneous hepatic bleeding is discussed.
\end{abstract}

\section{Introduction}

Massive intraperitoneal bleeding is a dramatic surgical emergency which results most frequently from trauma, or gynaecological complaints, particularly tubal ectopic pregnancy (Adinolfi et al., 1982). On rare occasions the liver is the source of a haemoperitoneum. In a retrospective autopsy survey of fatal gastrointestinal bleeds over the period 1973-1983, eight cases of fatal haemoperitoneum due to a hepatic origin were identified.

\section{Case reports}

A list of the eight patients with haemoperitoneum is shown in Table I. A brief summary of their case histories follows.

\section{Case 1}

A 52 year old woman was admitted to hospital after a week's treatment with ampicillin for presumed acute cholecystitis with no improvement. On admission her temperature was $38^{\circ} \mathrm{C}$ and a right hypochondrial mass was palpable in addition to the presence of a tender liver enlarged to $2.5 \mathrm{~cm}$ below the costal margin. Escherichiacoli was grown from blood cultures. Systemic treatment was commenced with several antibiotics and metronidazole. On the third day in hospital she developed melaena and died suddenly.

At post mortem there were features of polycystic disease of the liver and kidneys. An inflammatory mass involved one of the larger cysts in the right hepatic lobe with transverse mesocolon and colon forming part of the wall of this abscess cavity. Copious haemorrhage had occurred into the cyst with some

Correspondence: A. Busuttil, M.D., F.R.C.Path, D.M.J. Accepted: 7 July 1986 leakage into the abscess cavity, as well as massive intraperitoneal bleeding.

\section{Case 2}

A 61 year old man was referred to a medical outpatient clinic with loss of libido, weight loss and upper abdominal pain. He admitted to consuming at least $\frac{1}{2}$ litre of rum a day for several years. He was thin and icteric with numerous spider naevi, bilateral Dupuytren's contractures, peripheral oedema, ascites and a massively enlarged, hard, knobbly liver. A transcutaneous needle biopsy showed active cirrhosis complicated by a primary hepatocellular carcinoma. The alpha-feto protein level was $34,000 \mathrm{ng} / \mathrm{ml}$. He was discharged after investigation but was re-admitted as an emergency 4 weeks later having collapsed after a bout of abdominal pain; he died a few hours after admission. At autopsy there were 2 litres of blood within the peritoneal cavity. Active micronodular hepatic cirrhosis was confirmed in addition to a hepatocellular carcinoma occupying most of the right hepatic lobe and infiltrating both the portal and

Table I Hepatic pathology in fatal haemoperitoneum

\section{Cases}

Polycystic disease

Secondary tumours:

Poorly differentiated bronchial squamous carcinoma

Pancreatic adenocarcinoma

Malignant testicular teratoma ( 2 cases)

Post-cholecystectomy

Primary tumours:

Hepatocellular carcinoma

Haemangioendotheliosarcoma 
hepatic veins. This had ruptured on the undersurface of the liver over a $2 \mathrm{~cm}$ diameter area. No systemic metastases were present.

\section{Case 3}

A 55 year old woman gave a 2-month long history of generalized epigastric pain and nausea. On physical examination she appeared emaciated and the liver was irregularly enlarged to $4 \mathrm{~cm}$ below the costal margin. Ultrasonography showed two small calculi within the gall bladder and multiple hepatic metastases. A laparoscopy was performed and both lobes of the liver were biopsied. During this procedure she developed a cardiac arrest and failed to regain consciousness. At autopsy the metastases within the liver were shown to vary between 1 and $8 \mathrm{~cm}$ in diameter and the liver weighed $3,600 \mathrm{~g}$. These were shown to consist of poorly differentiated squamous carcinoma from a small primary bronchial tumour. A haemoperitoneum of about 2 litres was present and the oozing had occurred from the sites of needle biopsy of the liver.

\section{Case 4}

A 19 year old man was referred to an orthopaedic clinic with increasing backache and weight loss of $1 \mathrm{~kg}$ over a 3 week period. Spinal radiology showed osteolytic metastases. He was found to have a right testicular swelling which histologically was shown to be a choriocarcinoma (malignant teratoma trophoblastic). Combination chemotherapy with vincristine, bleomycin and cis-platinum was commenced after the orchidectomy but he died suddenly after an episode of abdominal pain and vomiting. The 3-litre haemoperitoneum found at post-mortem examination was due to rupture of a metastatic deposit within the liver. In addition this tumour had disseminated to the lungs, pleurae, ribs, vertebral bodies and extra-dural space.

\section{Case 5}

A 38 year old man presented with an increasing right testicular swelling of a year's duration. An orchidectomy showed the tumour to be an embryonal carcinoma (malignant teratoma intermediate). The lymphangiogram at this time showed para-aortic nodal spread and these nodes were irradiated. Over the next few months he developed rib, pulmonary and vertebral metastases which were also irradiated. Treatment with a combination of vincristine and bleomycin was also commenced. He died suddenly from ruptured liver metastases and secondary intraperitoneal bleeding about 11 months after diagnosis. Metastases were also present in the lungs, axial and peripheral skeleton, liver and lymph nodes.

\section{Case 6}

A 57 year old man was admitted for an elective cholecystectomy. Post-operatively he failed to recover from the anaesthetic and died after 24 hours. At autopsy he was shown to have oozed about $1 \frac{1}{2}$ litres of blood into the peritoneal cavity from the gall bladder bed.

\section{Case 7}

A 67 year old woman presented as an emergency after a bout of colicky pain and pyrexia. A laparotomy was performed which showed adenocarcinoma of the head of the pancreas with nodal and hepatic spread and a haemoperitoneum of unidentified origin. She died suddenly 2 days post-operatively. At autopsy a subcapsular haematoma was present at the site of one of the hepatic secondaries on the undersurface of the right hepatic lobe - one litre of blood had collected within the peritoneal cavity as a result of the rupture.

\section{Case 8}

A 64 year old woman made an uneventful recovery after a cholecystectomy. Two months later she collapsed at home and was re-admitted with an 'acute abdomen'. A haemoperitoneum was present af laparotomy and tumour tissue was shown to be replacing the liver and pelvic organs. She died 3 days later after developing features of shock. A 3-litre? volume of largely fluid blood was found inside the peritoneal cavity. The tumour found to be originating in the left lobe of the liver was shown to be a haemangioendotheliosarcoma. It had spread along the paracolic gutters to the ovaries and uterus, and systemically to the thyroid, adrenals and mesenteric lymph nodes, as well as ulcerated extensively through Glisson's capsule.

\section{Discussion}

Spontaneous non-traumatic hepatic rupture is known to occur uncommonly during pregnancy (HakimElahi, 1965) and in infants (Bradley \& Jarrett, 1936) for no readily apparent pathological cause. Congestion and inflammation of the hepatic parenchyma encountered in reticuloendothelial diseases such as advanced malaria makes hepatic rupture following minimal trauma of the enlarged liver more likely. Inflammatory changes associated with immunological disorders such as periarteritis nodosa (Dwonczyk et al., 1959) or a generalized Shwartzmann phenomenon (Huttunen et al., 1975) may also raise the tension within Glisson's capsule to a level sufficient to produce rupture of the liver, apparently spontaneously. 
Cavernous haemangiomas of the liver are common hepatic hamartomas but although they are very vascular they rarely attain a large size and bleeding from them is uncommon. The association of a haemoperitoneum with polycystic liver disease described in this paper, appears not to have been documented previously.

A well recognized complication of primary hepatic tumour is spontaneous liver rupture with secondary intraperitoneal bleeding. Pack \& Islami (1965) estimated that $5-10 \%$ of all hepatomas undergo spontaneous rupture. The pathogenesis postulated by Ong \& Taw (1972) is that as the tumour grows, its efferent venous drainage is occluded while the hepatic arterial supply is maintained producing marked engorgement of the tumour which is further enhanced due to intratumoral shunting (Watnaby et al., 1963); a consequent tamponade effect ensues with eventual vascular rupture, intratumoral bleeding, increased intratumoral tension and finally erosion of Glisson's capsule with direct bleeding into the peritoneal cavity. Furthermore, as a proportion of these tumours are associated with considerable hepatic dysfunction and often cirrhosis, decreased production of coagulation factors further exacerbates any bleeding.

Long-term oral contraceptives, androgenic and anabolic steroid administration has been shown to be associated with an increased incidence of nodular hyperplasia of the liver, hepatic adenomas and hepatocellular carcinomas (Glassberg \& Rosenbaum, 1976; Henderson et al., 1983). More commonly these hormones also induce vascular changes in the liver varying from focal dilatation of the periportal sinusoids to the presence of large parenchymal channels engorged with blood, the condition known as peliosis hepatis (Winkler \& Poulsen, 1975; Zafrani et al., 1983). Such neoplastic and vascular hepatic changes render the liver more prone to rupture and may produce a haemoperitoneum.

Primary hepatic haemangioendotheliosarcomas which result from exposure to polyvinyl chloride, thorotrast or arsenicals are by their very nature extensively vascularized due to intratumoral sinusoidal formation. Thromboses with focal tumoral infarction and spontaneous bleeding within the

\section{References}

ADINOLFI, Q., DE NUPTIIS, T., DE LUCA, P., CAPONE, Q. \& BONAFIGLIA, R. (1982). Osservazioni di relievi su 109 casi di emoperitoneo riscontrati nel periodo 1970-1981. Archivi di Ostetricia e Gynecologia, 5, 193.

AHMED, A. \& METCALFE-GIBSON, C. (1972). Haemoperitoneum complicating secondary carcinoma of the liver. British Journal of Surgery, 59, 576.

BETTINI, U. (1956). Rare osservazioni di rottura spontanea del fegato, con consequente emiperitoneo in corso di tumours are also frequent (McSween et al., 1973): secondary intraperitoneal rupture follows occasionally.

Metastatic hepatic nodules are extremely common but their intraperitoneal rupture and haemorrhage are reported very infrequently (Giardin et al., 1982). The tumours reported to have been associated with this complication include primary adrenocortical carcinoma (Giardin et al., 1982), pancreatic adenocarcinoma (Ahmed \& Metcalfe-Gibson, 1972), malignant melanoma (Caneghe \& Gelb, 1970; Coopermann et al., 1976) and prostatic adenocarcinoma (DeFaria, 1954). Angiographically hepatic metastatic deposits usually show a decreased rather than an increased vascularity with the tumour growth frequently outstripping its circulatory input and showing focal infarction and necrosis. Watson \& Baltaxe (1971) demonstrated by angiographic procedures a depleted blood supply in most metastases with the exception of tumours of endocrine, renal and testicular origins. The immediate cause of the hepatic rupture is a sudden increase in intra-abdominal pressure such as occurs with sneezing, coughing or straining (Bettini, 1956).

Bleeding from the liver after surgical procedures or biopsy is uncommon. Haemorrhagic incidents following percutaneous hepatic biopsy occur once for 10,000 biopsies (Chivrac \& Capron, 1978), and these are mostly in the nature of localized subcapsular haematomas which resolve spontaneously and are rarely fatal (Raines et al., 1974). In the cases herein described where intraperitoneal bleeding occurred after a biopsy, the poor pre-operative physical state of the patients probably accounted for this post-surgical complication.

Intraperitoneal bleeding complicating hepatic pathology is rare and the condition is often diagnosed on the autopsy table. The increasing incidence of primary hepatic tumours due to exposure to steroids and industrial poisons, and the longer survival of patients with disseminated carcinomatosis, will render the complication more frequent in the years to come. As some of the patients may be amenable to surgical treatment, the condition should be added to the differential diagnosis of a haemoperitoneum.

carcinomi primitivi e secondari dell'organo. Archivi di Vecchi Anatomia e Pathologia, 25, 345.

BRADLEY, G.F. \& JARRETT, D.E. (1936). Spontaneous rupture of a liver in a child with complete recovery. Journal of Pediatrics, 9, 776.

CANEGHE, M.AV. \& GELB, A.M. (1970). Hepatic rupture and haemorrhage from metastatic carcinoma of the liver. New York State Journal of Medicine, 70, 303.

CHIVRAC, D. \& CAPRON, J.P. (1978). Les complications de la 
ponction-biopsie hepatique transcutanee. Gastroenterologie Clinique Biologique, 2, 843.

COOPERMANN, A.H., WEILAND, L.H. \& WELCH, J.S. (1976). Massive bleeding from a ruptured metastatic hepatic melanoma treated by hepatic lobectomy. Mayo Clinic Proceedings, 51, 167.

DeFARIA, G. (1954). Cancer da prostata e morte per hemoperitonio resultante da rotura de nodello metastatico do figado. Revista Brasiliana Clinica, 27, 35.

DWONCZYK, J., SERLIN, O. \& SKERRETT, P.V. (1959). Spontaneous rupture of the liver - a report of a case secondary to polyarteritis nodosa. Annals of Surgery, 150, 327.

GIARDIN, M.F.S-M., CHAVANETTE, M.J. \& METREAU, J.M. (1982). Hemoperitoine et cancer secondaire du foie. Gastroenterologie Clinique Biologique, 6, 135.

GLASSBERG, A.B. \& ROSENBAUM, E.H. (1976). Oral contraceptives and malignant hepatoma. Lancet, i, 479.

HAKIM-ELAHI, E. (1965). Spontaneous rupture of a liver in pregnancy - report of a case and review of the literature. Obstetrics and Gynecology, 26, 435.

HENDERSON, B.E., PRESTON-MARTIN, S., EDMONDSON, H.A., PETERS, R.L. \& PIKE, M.C. (1983). Hepatocellular carcinoma and oral contraceptives. British Journal of Cancer, 48, 437.

HUTTUNEN, R., SEPPÄCÄ, A. \& MOKKA, R. (1975). Spontaneous rupture of the liver and spleen - report of a successfully treated case with an immunopathological reaction. Surgery, 77, 722.

MACSWEEN, R.N.M., VETTERS, J.M., ROSS, S.K., FERGUSON, J., JOHNSTONE, S.M. \& SANDISON, A.T. (1973). Haemangioendotheliosarcoma of the liver. Journal of Pathology, 109, 39.

ONG, G.B. \& TAW, J.L. (1972). Spontaneous rupture of hepatocellular carcinoma. British Medical Journal, 4, 146.

PACK, G.T. \& ISLAMI, A.H. (1965). Surgical treatment of hepatic tumours. Progress in Liver Diseases, $2,499$.

RAINES, D.R., VAN HEERTUM, R.L. \& JOHNSTON, C.R. (1974). Intrahepatic hematoma; a complication of percutaneous liver biopsy. Gastroenterology, 67, 284.

WATNABY, K.M., BOUCHIER, I.A.D., POPE, C.E. \& SHERLOCK, S. (1963). Hepatic blood flow in patients with metastases of the liver. Gastroenterology, 44, 735.

WATSON, C.R. \& BALTAXE, H.A. (1971). The angiographic appearance of primary and secondary tumours of the liver. Radiology, 101, 539.

WINKLER, A. \& POULSEN, H. (1975). Liver disease with periportal sinusoidal dilatation. A possible complication of oral contraceptive steroids. Scandinavian Journal of Gastroenterology, 10, 699.

ZAFRANI, E.S., PINAGDEAU, Y. \& DHUNEAUX, D. (1983). Drug induced vascular lesions of the liver. Archives of Internal Medicine, 143, 495. 